2P157

\section{高負荷におけるバクテリアベん毛モーターの回転ステップ 解析}

Sub-14 ${ }^{\circ}$ steps of the bacterial flagellar motors at high load

Yuichi Inoue, Hajime Fukuoka, Hiroto Takahashi, Akihiko Ishijima (IMRAM, Tohoku University)

Bacterial flagellar motor is a rotary motor with unitary steps of $\sim 14^{\circ}$ at low load (Sowa et al., 2005). We developed a simple method to detect the motor steps at high load using an elliptic probe (Annual meeting, 2013).

To understand the mechanism of the motor rotation, here we analyzed the steps at high load. With decreasing concentration of external sodium ion, rotational speed of the sodium-driven motor reduced until the motor showed unstable angular change, due to angular diffusion in the absence of stator complex. Histograms of the angular change showed the $\sim 7^{\circ}$ steps as well as the reported steps of $\sim 14^{\circ}$, suggesting that the motor rotation is based on the stator-independent steps of $<14^{\circ}$.

A novel role of dynactin for dynein motility revealed by gliding assay

Takuya Kobayashi, Hatsuha Kajita, Kei Saito, Yoko Y Toyoshima (Grad. Sch. of Arts and Sci., Univ. of Tokyo)

Dynactin is multi molecular protein complex and mediates dynein and the transporting cargo and regulates dynein motility. Although the coiled-coil 1 (CC1) region of dynactin p150 is known to bind dynein, the details of p150 binding to dynein motility has not been elucidated.

Because the $\mathrm{CC} 1$ region is extruded from the dynactin head, we produced the $\mathrm{CC} 1$ fragment and characterized. We performed in vitro motility assay in the presence of $\mathrm{CC} 1$ fragment and found that microtubule dissociation was increased by $\mathrm{CC} 1$ fragment. The remaining microtubules moved faster than the condition without $\mathrm{CC} 1$ fragment. Although it has been thought that dynactin is a simple activator, these results suggest that dynactin is a complicated regulator for dynein motility.
2P160

\section{ダイニン·微小管複合体の DNA 折り紙による架橋}

Cross-linking the dynein-microtubule complex by DNA origami

Keiko Hirose ${ }^{1}$, Kangmin Yan ${ }^{1}$, Hisashi Tadakuma ${ }^{2}$ ( ${ }^{1}$ Biomed. Res. Inst., AIST, ${ }^{2}$ Grad. Sch. Frontier Sci., Univ. Tokyo)

To understand how dynein produces force and moves along a microtubule, it is necessary to observe the structural changes of dynein molecules during force production. However, the dynein-microtubule complex, which has been used for electron microscopic observation of dynein in microtubulebound states, tends to disassemble when ATP is added to induce movement. To prevent disassembly, we cross-linked the microtubules using DNA origami structures. DNA origami tube structures were biotinylated at both ends, and bound to biotinylated microtubules via streptavidin. Cryo-electron microscopic images showed bundles of microtubules with bound dynein and DNA origami both in the presence and absence of ATP.

Heev Ayade ${ }^{1}$, Irwin Zaid ${ }^{2}$, Julia Yeomans ${ }^{2}$, Daisuke Mizuno ${ }^{1}\left({ }^{1}\right.$ Kyushu University, ${ }^{2}$ University of $O x$ ford)

In a reconstituted active gel, a single myosin which acts as a contractile force generator drives athermally the probe particles located at a separation distance $r$ away from the myosin. The probe particles sense a displacement field proportional to $1 / \mathrm{r} 2$ coming from the myosin which is in continuum, elastic actin network. The non-equilibrium statistics and dynamics of active gel are investigated by analyzing the non-Gauss athermal fluctuations of probe particles. We found out that the full positional probability density distribution of probe particles follows the truncated Levy distribution with a characteristic exponent of 1.5 . molecule assay

Takuya Miyashita, Takuya Kobayashi, Hatsuha Kajita, Yoko Y. Toyoshima (Grad. Sch. of Arts \& Sci., Univ. of Tokyo)

Dynactin is thought to interact with dynein motor protein by binding to it directly. Single-molecule assay of dynactin complex by total internal reflection fluorescence (TIRF) microscopy revealed that exon 5-7 present in the basic domain of dynactin p150 is necessary for binding and interaction between microtubules and dynactin. We found that coiled-coil domain $(\mathrm{CC} 1)$ of $\mathrm{p} 150 \mathrm{~N}$-terminal, which binds to the $\mathrm{N}$-terminal region of dynein intermediate chain, caused dissociation of dynein from microtubules by TIRF W-view imaging of these proteins. Dynactin complex also dissociated dynein from microtubules as with $\mathrm{CC} 1$, indicating that $\mathrm{CC} 1$ dissociate dynein from microtubules. This study demonstrates $\mathrm{CC} 1$ is intrinsically important to regulation of dynein motility by dynactin.

\section{P162}

\section{軸糸ダイニンが駆動する微小管が創出する in vitro での動的 渦形成}

In vitro dynamic vortex formation of microtubules driven by axonemal dyneins

Naoki Kanatani ${ }^{1}$, Hiroaki Kojima ${ }^{2}$, Kazuhiro Oiwa ${ }^{1,2,3}$ ( ${ }^{1}$ Grad. Sch. Sci., Univ. Hyogo, ${ }^{2} A d v$. ICT Res. Inst, NICT, $\left.{ }^{3} J S T, C R E S T\right)$

We found in vitro self-organized pattern formation of fluorescently-labeled microtubules driven by inner-arm dynein subspecies $\mathrm{c}$ and $\mathrm{g}$ of Chlamydomonas. These dyneins attached on a glass surface at densities higher than 1000 molecules/um2, are capable of moving microtubules on glass surface at velocities of $6-12 \mathrm{um} / \mathrm{sec}$ in the presence of $1 \mathrm{mM} \mathrm{Mg}$ ATP at $23 \mathrm{C}$. Microtubules moving on the surface often collide with each other and are gradually aligned and form streams. The behavior of microtubules in the collision is nematic. These microtubule streams grow into vortices with the diameter of 200-500 um and finally the vortices form arrays covering the surface of a whole flow cell. We have investigated biological factors which determine parameters of this vortex formation. 